\title{
Catalase activity is necessary for heat-shock recovery in Aspergillus nidulans germlings
}

\author{
Maria Antônia Noventa-Jordão, ${ }^{1}$ Ricardo M. Couto, ${ }^{1}$ \\ Maria Helena S. Goldman, ${ }^{2}$ Jesus Aguirre, ${ }^{3}$ Suresh lyer, ${ }^{4}$ Allan Caplan, ${ }^{4}$ \\ Hector F. Terenzi ${ }^{2}$ and Gustavo H. Goldman ${ }^{1}$
}

Author for correspondence: Gustavo H. Goldman. Tel: +55 16 6024280/81. Fax: +55 16 6331092/6024280. e-mail: ggoldman@usp.br

\author{
1 Faculdade de Ciências \\ Farmacêuticas de Ribeirão \\ Preto, Universidade de São \\ Paulo and Universidade de \\ Franca, Av. do Café S/N, CEP \\ 14040-903, Ribeirão Preto, \\ São Paulo, Brazil \\ 2 Faculdade de Filosofia, \\ Ciências e Letras de \\ Ribeirão Preto, \\ Universidade de São Paulo, \\ São Paulo, Brazil \\ 3 Instituto de Fisiologia \\ Celular-UNAM, \\ Mexico City, Mexico \\ 4 Department of \\ Microbiology, Molecular \\ Biology, and Biochemistry, \\ University of Idaho, \\ Moscow, ID, USA
}

\begin{abstract}
To understand the molecular mechanisms induced by stress that contribute to the development of tolerance in eukaryotic cells, the filamentous fungus Aspergillus nidulans has been chosen as a model system. Here, the response of A. nidulans germlings to heat shock is reported. The heat treatment dramatically increased the concentration of trehalose and induced the accumulation of mannitol and mRNA from the catalase gene catA. Both mannitol and catalase function to protect cells from different reactive oxygen species. Treatment with hydrogen peroxide increased $A$. nidulans germling viability after heat shock whilst mutants deficient in catalase were more sensitive to a $50{ }^{\circ} \mathrm{C}$ heat exposure. It is concluded that the defence against the lethal effects of heat exposure can be correlated with the activity of the defence system against oxidative stress.
\end{abstract}

Keywords: catalase, heat shock, stress tolerance, Aspergillus nidulans

\section{INTRODUCTION}

Living cells display a rapid molecular response when exposed to adverse environmental conditions. Almost all cells have the ability to react to sudden changes in temperature, changes in osmotic pressure, starvation conditions and numerous other forms of stress commonly encountered during their lifespan. One set of responses involves changes at the transcriptional level to enhance the production of proteins that are able to protect the cell against damage (Mager \& De Kruijff, 1995). In recent years, most of the attention has been directed to the molecular events induced after a shift to high temperature: the heat-shock response. The most dramatic manifestation of the heat-shock response is the strong induction of heat-shock proteins and - in Saccharomyces cerevisiae and Neurospora crassa-accumulation of a large cytoplasmic pool of trehalose (Thevelein, 1996; Jorge et al., 1997). Several other biochemical and physiological changes occur at the same time (Piper, 1997), but the main factors causing death after heat exposure are still unknown.

Oxidative stress is the result of an imbalance between pro-oxidant species and the levels of the defences

Abbreviation: ROS, reactive oxygen species. resulting from the generation of reactive oxygen species (ROS) (Santoro \& Thiele, 1997). ROS, including the superoxide anion $\left(\mathrm{O}_{2}^{-}\right)$, hydrogen peroxide $\left(\mathrm{H}_{2} \mathrm{O}_{2}\right)$ and the hydroxyl radical $\left(\mathrm{OH}^{*}\right)$, are noted for their ability to alter or inactivate proteins, lipid membranes and DNA by reacting chemically with them. Biological systems have evolved several defence mechanisms that enable cells to cope with lethal oxidative environments (Moradas-Ferreira et al., 1996). These antioxidant defence systems include enzymic activities such as superoxide dismutase and catalase, which detoxify $\mathrm{O}_{2}^{-}$ and $\mathrm{H}_{2} \mathrm{O}_{2}$, respectively, and non-enzymic protective molecules including glutathione, vitamins $\mathrm{C}$ and $\mathrm{E}$, and uric acid (Scandalios, 1990). In addition to the induction of proteins directly involved in detoxifying and repairing damage by oxidants and free radical species, some of the inducible proteins overlap with heat-shock-inducible polypeptides. For example, a Salmonella typhimurium oxyR1 mutant selected under oxidative conditions and resistant to $\mathrm{H}_{2} \mathrm{O}_{2}$ constitutively overexpresses five heatshock proteins (Morgan et al., 1986). The oxidative stress response and its relationship to the heat-shock phenomenon have also been intensively investigated in the eukaryotic organism S. cerevisiae (Jamieson et al., 1994; Davidson et al., 1996). Experiments with promoter fusions have demonstrated that one of the heat-inducible forms of HSP70 from $S$. cerevisiae is inducible with 
$\mathrm{H}_{2} \mathrm{O}_{2}$ (Jamieson et al., 1994). Recently, Godon et al. (1998) analysed by comparative two-dimensional gel electrophoresis of total cell proteins the changes in gene expression underlying the yeast adaptative stress response to $\mathrm{H}_{2} \mathrm{O}_{2}$. The hydrogen-peroxide-responsive targets include a number of heat-shock proteins and proteins with reactive oxygen intermediate scavenging activities.

Here, we have examined the relationship between the heat-shock response and the response to peroxide treatment in Aspergillus nidulans germlings in order to investigate whether oxidative stress is involved in the lethal effect of heat exposure. We show that hydrogen peroxide treatment actually increases $A$. nidulans germling viability when cells are exposed to a heat shock. In addition, mutants deficient in the key antioxidant enzyme catalase are more sensitive to a $50{ }^{\circ} \mathrm{C}$ heat exposure.

\section{METHODS}

Strains, plasmids and growth conditions. The A. nidulans strains used were R21 ( $y A 1$ pabaA1), TWA22 (pabaA1 yA2 $\arg B \operatorname{trp} C 801$ veA1), TRN1 (pabaA1 $y A 2 \arg B \operatorname{cat} A:: \arg B$ trpC801 veA1), TLK12 (pabaA1 yA2 $\arg B$ catB:: $\arg B$ veA1) and CLK20 (biA1 cat $A:: \arg B$ metG1 catB::argB veA1). The medium used was complete medium (YAG; 2\% glucose, $0.5 \%$ yeast extract, $2 \%$ agar, trace elements). Trace elements, vitamins and nitrate salts were as described by Kafer (1977). Conidia were used to inoculate liquid cultures $\left(1 \times 10^{8}\right.$ conidia $\mathrm{ml}^{-1}$ ), which were incubated in a reciprocal shaker at $37^{\circ} \mathrm{C}$ for $6 \mathrm{~h}$. The cat $A$ and $c a t B$ genes were obtained from the plasmids pCAN5 and pDW2, respectively (Navarro et al. 1996; Kawasaki et al., 1997).

Gas chromatography analysis of $\boldsymbol{A}$. nidulans cell extracts. Approximately $0 \cdot 1 \mathrm{~g}$ dried mycelium was boiled in $10 \mathrm{ml} 80 \%$ ethanol with $100 \mu \mathrm{g} \alpha$-D-phenyl glucopyranoside $\mathrm{ml}^{-1}$ (added as an internal standard) in a tube, then centrifuged at $7900 \mathrm{~g}$ for $10 \mathrm{~min}$ to pellet the insoluble debris. The debris was washed twice with $80 \%$ ethanol. The washes were combined with the initial supernatant and passed through an activated Sep-Pak Plus C-18 cartridge (Waters; WAT020515) and evaporated to dryness in a vacuum oven at $60{ }^{\circ} \mathrm{C}$.

The dried extracts were derivatized using a modification of standard protocols (Sweeley et al., 1963; Brobst \& Lott, 1966). Briefly, $15 \mu \mathrm{l}$ 2-dimethylaminoethanol and $400 \mu \mathrm{l}$ pyridine containing $30 \mathrm{mg}$ methoxyamine $\mathrm{ml}^{-1}$ were added to each dried extract. The vials were then capped and heated to $75-80{ }^{\circ} \mathrm{C}$ for $1 \mathrm{~h}$, then allowed to cool to room temperature. After cooling, $20 \mu \mathrm{l}$ trifluoroacetic acid and $400 \mu \mathrm{l}$ hexamethyldisilazane were added. The contents were mixed, then incubated for $1 \mathrm{~h}$ at room temperature. The insoluble material was removed by centrifuging at $15000 \mathrm{~g}$ for $5 \mathrm{~min}$ and the supernatant was transferred to a clean vial.

Derivatized samples were separated on a Hewlett Packard HP 5890 series II Gas Chromatograph with a $30 \mathrm{~cm}$ CP-SIL 8 C8MS column (Chrompack 5860) and detected with an HP 5989A mass spectrometer. Retention times and derivatization efficiencies were established using solutions of known composition for requested compounds. Total peak areas were corrected for derivatization efficiency and weight of material processed to arrive at $\mu \mathrm{g}$ (g dry weight $)^{-1}$ values.
Heat and oxidative stress treatments. Six-hour-old germlings were heat-shocked by incubating them at $50{ }^{\circ} \mathrm{C}$ for 30,45 and $60 \mathrm{~min}$. Oxidative stress treatments were performed by incubating 6-h-old germlings (heat-shocked or non-heatshocked) in $50 \mathrm{mM}$ hydrogen peroxide for $20 \mathrm{~min}$ at $37^{\circ} \mathrm{C}$. In all cases appropriate dilutions were made and $100 \mu \mathrm{l}$ aliquots spread on plates of YAG medium containing $0.01 \%$ Triton X100 to restrict colony growth (Donnely et al., 1994).

DNA and RNA manipulations. Restriction enzyme digests and DNA ligations were performed in accordance with the suppliers' (Boehringer and Amersham Pharmacia) recommendations. Plasmid DNA isolation from Escherichia coli was performed using standard procedures (Sambrook et al., 1989). DNA probes were constructed using a random primer system according to the manufacturer (Boehringer).

For Northern analysis, A. nidulans mycelia from the heat and oxidative stress treatments were harvested by filtration through a Whatman no. 1 filter, washed thoroughly with sterile water, disrupted and total RNA extracted (Sambrook et al., 1989). Twenty micrograms of RNA from each treatment were then fractionated in a $2 \cdot 2 \mathrm{M}$ formaldehyde, $1.5 \%$ agarose gel and then transferred to Hybond-N + filters (Amersham) in the presence of $20 \times$ SSPE $(3.5 \mathrm{M} \mathrm{NaCl}, 0.2 \mathrm{M}$ sodium phosphate $\mathrm{pH} 7 \cdot 7,0 \cdot 02 \mathrm{M}$ disodium EDTA). Prehybridization and hybridization were performed according to Sambrook et al. (1989).

\section{RESULTS AND DISCUSSION}

We addressed the problem of whether oxidative stress contributes to the lethality of heat shock in A. nidulans germlings. As a first step, germlings were heat-shocked at $50{ }^{\circ} \mathrm{C}$ for various periods of time. Three independent experiments showed that about $65 \%$ of the germlings survived after $30 \mathrm{~min}$ of heat shock at $50{ }^{\circ} \mathrm{C}$, whilst after 45 and $60 \mathrm{~min}$ of exposure the viability of germlings dropped to $3 \%$ and $1 \%$, respectively (Fig. 1a). In yeast, the ubiquitin gene is induced by stress conditions, including hyperthermic stress (Piper, 1997). Here, we used one of the ubiquitin genes (ubi1) from A. nidulans (M. A. Noventa-Jordão, unpublished) in Northern blot experiments. As shown in Fig. 1(a), the ubiquitin gene was induced about fivefold after $60 \mathrm{~min}$ of heat-shock treatment. This result demonstrates that our heat-shock conditions were disturbing cell function sufficiently to elicit a standard stress response. We decided to perform additional experiments to characterize other biochemical processes contributing to the associated defence processes.

Cell extracts prepared from the germlings subjected to 30 and $60 \mathrm{~min}$ heat-shock exposure were dried and analysed by gas chromatography. As shown in Table 1, the heat treatment dramatically increased the concentration of both mannitol and trehalose. Trehalose has been shown in S. cerevisiae and N. crassa to accumulate after a sublethal heat treatment and a close correlation between trehalose content and resistance to heat shock has been demonstrated (Thevelein, 1996; Jorge et al., 1997). Mannitol has been widely used to scavenge $\mathrm{OH}^{*}$ radicals generated by the phagocyte respiratory burst or by cell-free oxidant systems (Tauber \& Babior, 1977). Chaturvedi et al. (1997) demonstrated that $S$. cerevisiae 


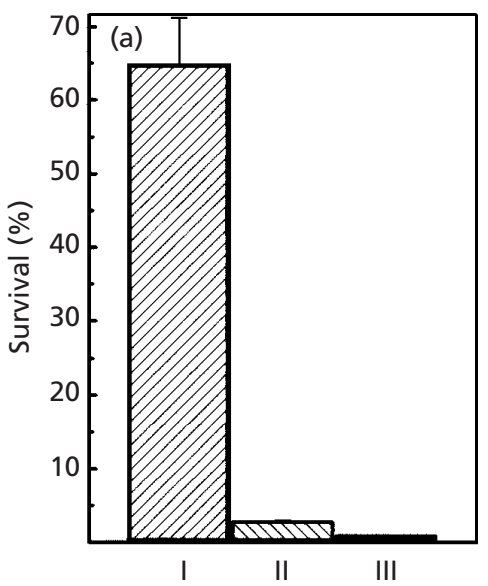

(b) Control Heat shock (min)
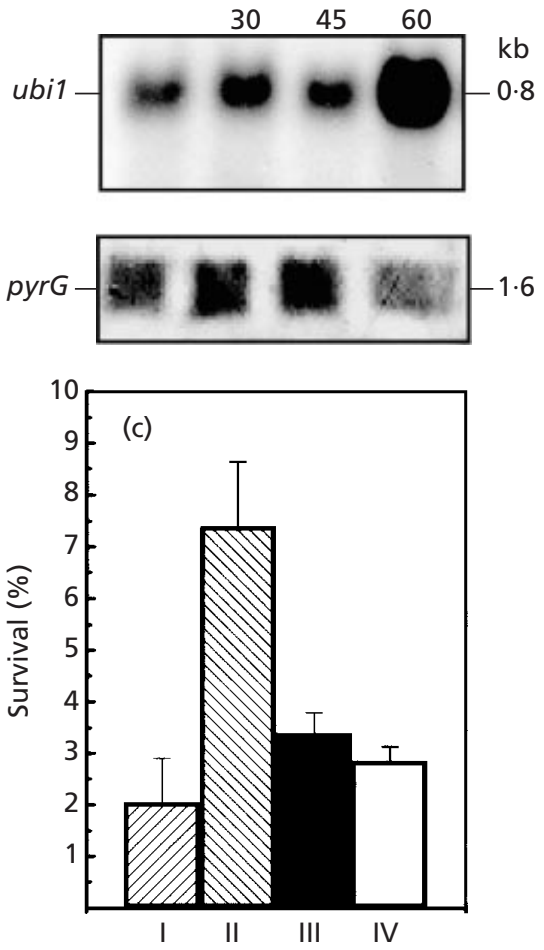

Fig. 1. Effect of hydrogen peroxide on the heat-shock survival of $A$. nidulans R21 germlings. (a) Six-hour-old germlings were heat-shocked at $50{ }^{\circ} \mathrm{C}$ for either 30 (treatment I), 45 (treatment II) or 60 (treatment III) min. (b) Northern blot of the total RNA obtained during heat-shock experiments. The upper panel is the Northern analysis of the ubiquitin (ubi1) gene from $A$. nidulans using total RNA extracted from 6-h-old germlings before heat shock (control), and after 30, 45 and 60 min of heat shock at $50^{\circ} \mathrm{C}$. The lower panel shows the same blot hybridized with the pyrG gene from $A$. nidulans as RNA loading control. (c) Six-hour-old germlings were heat-shocked at $50{ }^{\circ} \mathrm{C}$ for $45 \mathrm{~min}$ (treatment I), or heat-shocked at $50^{\circ} \mathrm{C}$ for $45 \mathrm{~min}$ and either transferred to hydrogen peroxide $50 \mathrm{mM}$ for $20 \mathrm{~min}$ (treatment II) or paraquat $5 \mathrm{mM}$ for $20 \mathrm{~min}$ (treatment IV), and then allowed to grow in complete medium. Alternatively, germlings were incubated in hydrogen peroxide $50 \mathrm{mM}$ for $20 \mathrm{~min}$ and heat-shocked at $50^{\circ} \mathrm{C}$ for 45 min (treatment III) Results in (a) and (c) are means of three independent experiments \pm SD.
Table 1. Composition of heat-shocked Aspergillus nidulans germlings as determined by gas chromatography

Experiments were repeated twice and representative results are given. Values are expressed in $\mu \mathrm{g}$ (g dry wt mycelium $)^{-1}$. ND, Not detectable.

\begin{tabular}{|lccc|}
\hline & \multicolumn{3}{c|}{ Length of heat shock (min) } \\
\cline { 2 - 4 } & $\mathbf{0}$ & $\mathbf{3 0}$ & $\mathbf{6 0}$ \\
\hline Succinic acid & $\mathrm{ND}$ & $\mathrm{ND}$ & $24 \cdot 0$ \\
Fumaric acid & $\mathrm{ND}$ & $\mathrm{ND}$ & $85 \cdot 0$ \\
Malic acid & $24 \cdot 8$ & $24 \cdot 8$ & $60 \cdot 0$ \\
Salycilic acid & $142 \cdot 0$ & $94 \cdot 0$ & $162 \cdot 0$ \\
Arabitol & $14 \cdot 0$ & $9 \cdot 9$ & $19 \cdot 5$ \\
Fructose & $12 \cdot 6$ & $12 \cdot 0$ & $19 \cdot 5$ \\
Glucose & $219 \cdot 0$ & $124 \cdot 0$ & $315 \cdot 0$ \\
Mannitol & $345 \cdot 0$ & $1374 \cdot 0$ & $2623 \cdot 0$ \\
Sorbitol & $52 \cdot 8$ & $\mathrm{ND}$ & $\mathrm{ND}$ \\
Inositol & $\mathrm{ND}$ & $5 \cdot 0$ & $8 \cdot 6$ \\
Trehalose & $\mathrm{ND}$ & $1207 \cdot 0$ & $3307 \cdot 0$ \\
\hline
\end{tabular}

strains expressing the E. coli mannitol dehydrogenase gene and producing mannitol were more resistant to oxidative stress. These authors reasoned that polyols produced endogenously by fungi should scavenge oxidants generated by the phagocyte oxidative burst and that the ability of a fungus to synthesize and accumulate these polyols should allow it to resist phagocyte killing. In fact, a mannitol-underproducing mutant of the human fungal pathogen Cryptococcus neoformans was less virulent in mice and more susceptible to oxidative killing than was its wild-type parent (Chaturvedi et al., $1996 \mathrm{a}, \mathrm{b})$. On the basis of these studies, we postulated that the accumulation of mannitol in $A$. nidulans germlings may be an indication that recovery from heat shock depends in part on the activity of the oxidative stress defences. To test this possibility, ROS defences were induced in germlings immediately after they had been heat-shocked at $50^{\circ} \mathrm{C}$ for $45 \mathrm{~min}$. Consistent with our hypothesis, germlings which received a hydrogen peroxide treatment after heat shock survived considerably better than those subjected to heat shock alone ( $7 \cdot 4 \%$ as compared to $2 \%$; Fig. 1c). Germlings treated only with $50 \mathrm{mM}$ hydrogen peroxide for $20 \mathrm{~min}$ showed about $70 \%$ survival (see Fig. 3a). If the two types of stress responses were completely independent, the effect of combining the two treatments would be expected to reduce the survival rate below $2 \%$. Instead, the combination of treatments (heat shock plus hydrogen peroxide) increased survival about fourfold higher than heat-shock treatment alone. These differences were statistically significant (Student's $t$-test at $5 \%$ level). The treatment of germlings with another oxidative stress agent, the superoxide-generating fungicide paraquat, at $5 \mathrm{mM}$ for $20 \mathrm{~min}$ after the heat shock, was less effective than treating with peroxides, but still increased survival 1.7-fold compared to heat-shock treatment alone. This 


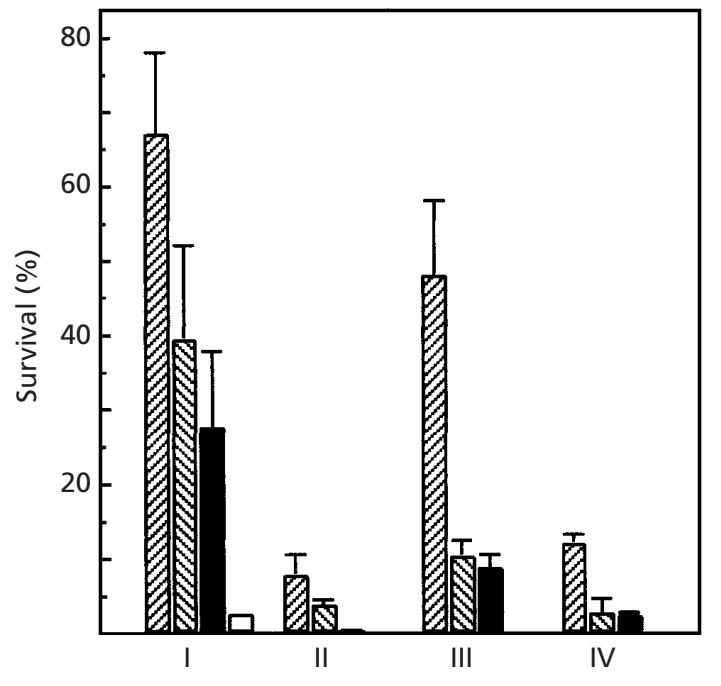

Fig. 2. Lethal heat survival assay. Six-hour-old germlings from the wild-type strain TWA22 (I), catA deletion strain (II), catB deletion strain (III) and catAcatB deletion strain (IV) were heat-

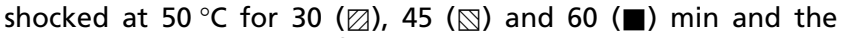
wild-type strain TWA22 for $75 \mathrm{~min}(\square)$, and then allowed to grow in complete medium. Results are means of three independent experiments \pm SD.

lower survival rate probably reflects the low germling survival rate (about $27 \%$ ) when incubated for $20 \mathrm{~min}$ in $5 \mathrm{mM}$ paraquat (data not shown).

We next tested how the order of consecutive stress treatments affected viability. We found that reversing the order of treatments by exposing germlings to $50 \mathrm{mM}$ hydrogen peroxide for 20 min before subjecting them to heat shock had essentially the same impact on germling survival as heat shock alone (Fig. 1c). The fact that the order of treatments affects the outcome may be an indication that the peroxide-induced defences are more sensitive to heat than the heat-induced gene products are to ROS. Much of the damage associated with oxidative stress results from protein and lipid modification. By comparison, much of the damage associated with heat shock results from protein and organellar denaturation. Some proteins induced by oxidative stress prior to heat may be denatured by heat shock and thus offer no additional protection. This is supported by studies described below that show that the hydrogen-peroxideinducible gene cat $B$ cannot be induced by that agent after heat-shock treatment. Taken together, the results reported here suggest that oxidative stress agents, such as hydrogen peroxide and paraquat, help A. nidulans germlings to recover from heat shock, presumably by inducing a more effective stress defence process than can be induced by heat alone.

In order to understand the mechanisms underlying such a process, we performed a similar set of experiments using catalase-deficient $A$. nidulans mutants. It is known that catalase genes have an important role in protecting cells against damage caused by oxidative and heat-shock stresses (Piper, 1997; Moradas-Ferreira et al., 1996; Davidson et al., 1996). Two catalase genes, cat $A$ and cat $B$, have been characterized in $A$. nidulans. The cat $A$ gene expresses a developmentally regulated catalase that accumulates to high levels in asexual and sexual spores (conidia and ascospores, respectively; Navarro et al., 1996; Navarro \& Aguirre, 1998), whilst catB expresses a catalase induced during vegetative mycelial growth and stationary phase (Kawasaki et al., 1997). The effect of mutations in cat $A$, cat $B$ and the double mutant cat $A$ $c a t B$ on cell survival was determined after heat shock at $50{ }^{\circ} \mathrm{C}$ for 30,45 and $60 \mathrm{~min}$, and $75 \mathrm{~min}$ for the wild-type strain TWA22 (Fig. 2). The catA mutant and the double mutant showed much less ability to recover from heat shock than the catB deletion strain, whilst this strain showed lower survival than the wild-type.

We also verified the importance of each catalase to the hydrogen-peroxide-enhanced survival of heat-shocked germlings. Firstly, we incubated A. nidulans germlings in $50 \mathrm{mM}$ hydrogen peroxide for various periods of time (Fig. 3a). Both the cat $A$ and the cat $A$ catB mutants displayed a high degree of hydrogen peroxide sensitivity, being completely killed after 15 min of incubation. The cat $B$ deletion mutant was less affected than the other two mutated strains. We also assessed the importance of both catalases during hydrogen peroxide post-treatment of A. nidulans heat-shocked germlings. The cat deletion mutants were constructed in strain TWA22, which is more resistant to the heat-shock treatment than the other wild-type strain, R21 (Figs 2 and 3b). Nevertheless, when treatments with the wild-type strain TWA22 were done at $50{ }^{\circ} \mathrm{C}$ for $75 \mathrm{~min}$, the survival was improved by exposing germlings to consecutive treatments of heat shock and hydrogen peroxide and this difference was statistically significant (Student's $t$-test at $5 \%$ level). The same behaviour was observed for the catB deletion mutant (Fig. 3b).

Since both catalase genes are thought to encode enzymically similar proteins, the treatment-dependent differences between cat $A$ and $\operatorname{cat} B$ phenotypes might be explained in one of two ways. Either each gene is induced by only one of the two inducers, or each is induced by both inducers but to very different levels. In order to distinguish between these two possibilities, we assayed steady-state levels of cat $A$ and catB mRNA after heat shock and after hydrogen peroxide treatment. We found that both messengers accumulated to low basal levels in unstressed cultures. On the other hand, cat $A$ mRNA did accumulate significantly upon heat shock and heat shock plus hydrogen peroxide treatments but not after hydrogen peroxide treatment alone. By contrast, cat $B$ mRNA accumulation was only induced upon hydrogen peroxide treatment (Fig. 4 and Kawasaki et al., 1997). Taken together, our results indicate that germling survival after either heat shock or oxidative stress depends primarily on the catA-encoded catalase. Based on the phenotypic analyses, we nevertheless conclude that cat $B$ contributes somewhat to cell survival in both conditions, despite the fact that it is not induced 

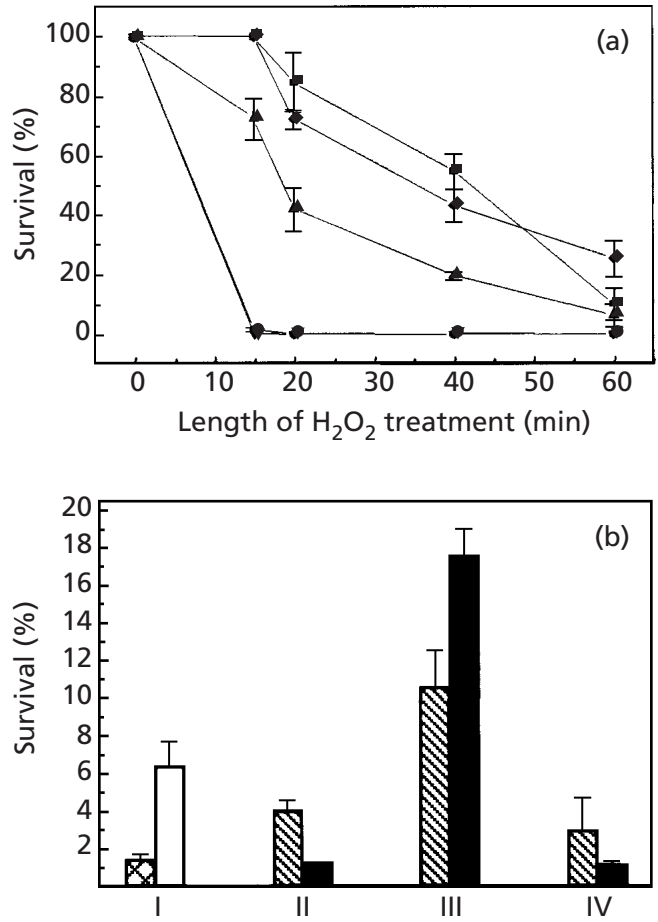

Fig. 3. (a) A. nidulans germling sensitivity to hydrogen peroxide. Six-hour-old germlings were incubated for different lengths of time in hydrogen peroxide and then allowed to grow in complete medium. $\mathbf{\square}$, Wild-type strain TWA22; wild-type strain $\mathrm{R} 21 ; \boldsymbol{0}$, cat $A$ deletion strain; $\boldsymbol{\Delta}$, cat $B$ deletion strain; $\boldsymbol{\nabla}$, cat $A$ cat $B$ deletion strain. (b) Effect of hydrogen peroxide on the heat-shock survival of $A$. nidulans germlings. Six-hour-old germlings from the wild-type strain TWA22 (I), cat $A$ deletion strain (II), cat $B$ deletion strain (III) and cat $A$ cat $B$ deletion strain (IV) were heat-shocked at $50{ }^{\circ} \mathrm{C}$ for $45 \mathrm{~min}(\mathbb{\nabla})$, or heat-shocked at $50^{\circ} \mathrm{C}$ for $45 \mathrm{~min}$ and transferred to hydrogen peroxide $50 \mathrm{mM}$ for $20 \mathrm{~min}(\square)$, and then allowed to grow in complete medium. The wild-type strain TWA22 is more resistant to the heat shock and consequently was heat-shocked at $50{ }^{\circ} \mathrm{C}$ for $75 \mathrm{~min}(\otimes)$ and transferred to hydrogen peroxide $50 \mathrm{mM}$ for $20 \mathrm{~min}(\square)$. Results are means of three independent experiments $\pm S D$.

significantly after heat stress. Our studies demonstrate the complexity of stress defence processes. Aspergillus germlings may accumulate small soluble molecules like trehalose to stabilize enzyme structure at high temperatures, but our results indicate that heat-shock-induced oxidative stress remains one of the major factors contributing to death of heat-treated cells. In order to protect themselves, germlings must accumulate agents such as mannitol and enzymes like catalase in order to scavenge some of the ROS that are produced by the interruption of normal electron transfer. The lack of catalase activity leads to an increase in formation of hydroxyl radicals as peroxide is not converted to water and oxygen. The increasing amount of hydroxyl radicals probably has the most damaging effect, although the diffusion of hydroxyl radicals is more limited than that of peroxide. Presumably, survival is also dependent on the production of additional antioxidant defences that are induced by $\mathrm{H}_{2} \mathrm{O}_{2}$ treatments although we have not
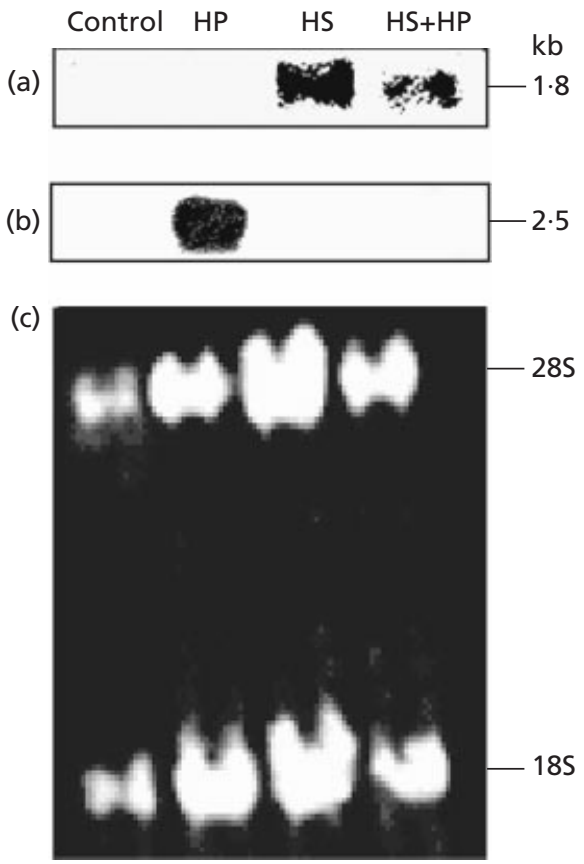

Fig. 4. Northern blot of the mRNA obtained during heat-shock experiments. Northern analysis of the catA (a) and cat $B$ (b) mRNAs from total RNA extracted from the 6-h-old germlings before heat shock (control), after hydrogen peroxide treatment (HP), after heat shock (HS) and after heat shock plus hydrogen peroxide treatment (HS + HP). Panel (c) shows the rRNAs on the blot used as an RNA loading control.

yet identified these components. Other results support this interpretation. Godon et al. (1998) have shown that during the yeast adaptive stress response to $\mathrm{H}_{2} \mathrm{O}_{2}$, a number of heat-shock proteins accumulate. Davidson et al. (1996) have shown that mutants deficient in the key antioxidant enzymes catalase, superoxide dismutase and cytochrome- $c$ peroxidase are sensitized to a $50{ }^{\circ} \mathrm{C}$ heat exposure, whilst overexpression of catalase and superoxide dismutase provides protection from lethal heat shock. The yeast cytoplasmic catalase $\mathrm{T}$ gene is under stress-response element (STRE) control with the result that catalase $\mathrm{T}$ is induced by heat shock except in cells with high protein kinase A activity. Lack of catalase T causes a small reduction in thermotolerance in both proliferating and stationary-phase cells except when kinase A activity levels are high (Piper, 1997; Wieser et al., 1991). These influences of the levels of different antioxidant activities on thermotolerance are thought to reflect the severity of ROS-induced damage to cellular proteins, nucleic acids and lipids that results from respiration at higher temperatures.

\section{ACKNOWLEDGEMENTS}

We thank FAPESP, CNPq-Brazil and ICGEB-UNIDO for financial support. S. Iyer and A. Caplan were funded by the NSF-Idaho EPSCoR programme and by NSF Cooperative Agreement Number EPS-9350539 


\section{REFERENCES}

Brobst, K. M. \& Lott, C. E., Jr (1966). Determination of some compounds in corn syrup by gas-liquid chromatography of the trimethylsilyl derivatives. Cereal Chem 43, 35-42.

Chaturvedi, V., Flynn, T., Niehaus, W. G. \& Wong, B. (1996a). Stress tolerance and pathogenic potential of a mannitol mutant of Cryptococcus neoformans. Microbiology 142, 937-943.

Chaturvedi, V., Wong, B. \& Newman, S. L. (1996b). Oxidative killing of Cryptococcus neoformans by human neutrophils: evidence that fungal mannitol protects by scavenging reactive oxygen intermediates. J Immunol 156, 3836-3840.

Chaturvedi, V., Bartiss, A. \& Wong, B. (1997). Expression of bacterial $m t l D$ in Saccharomyces cerevisiae results in mannitol synthesis and protects a glycerol-defective mutant from high-salt and oxidative stress. J Bacteriol 179, 157-162.

Davidson, J. F., Whyte, B., Bissinger, P. H. \& Schiestl, R. H. (1996). Oxidative stress is involved in heat-induced cell death in Saccharomyces cerevisiae. Proc Natl Acad Sci USA 93, 5116-5121.

Donnely, E., Barnett, Y. A. \& McCullough, W. (1994). Germinating conidiospores of Aspergillus amino acid auxotrophs are hypersensitive to heat shock, oxidative stress and DNA damage. FEBS Lett 355, 201-204.

Godon, C., Lagniel, G., Lee, J., Buhler, J. M., Kieffer, S., Perrot, M., Boucherie, H., Toledano, M. B. \& Labarre, J. (1998). The $\mathrm{H}_{2} \mathrm{O}_{2}$ stimulon in Saccharomyces cerevisiae. J Biol Chem 273, 2248022489.

Jamieson, D. J., Rivers, S. L. \& Stephen, D. W. S. (1994). Analysis of Saccharomyces cerevisiae proteins induced by peroxide and superoxide stress. Microbiology 140, 3277-3283.

Jorge, J. A., Polizeli, M. L. T. M., Thevelein, J. M. \& Terenzi, H. F. (1997). Trehalases and trehalose hydrolysis in fungi. FEMS Microbiol Lett 154, 165-171.

Kafer, E. (1977). Meiotic and mitotic recombination in Aspergillus and its chromosomal aberrations. Adv Genet 19, 33-131.

Kawasaki, L., Wysong, D., Diamond, R. \& Aguirre, J. (1997). Two divergent catalase genes are differentially regulated during Aspergillus nidulans development and oxidative stress. J Bacteriol 179, 3284-3292.

Mager, W. H. \& De Kruijff, A. J. J. (1995). Stress-induced transcriptional activation. Microbiol Rev 59, 506-531.
Moradas-Ferreira, P., Costa, V., Piper, P. \& Mager, W. (1996). The molecular defences against reactive oxygen species in yeast. Mol Microbiol 19, 651-658.

Morgan, R. W., Christman, M. F., Jacobson, F. S., Storz, G. \& Ames, B. N. (1986). Hydrogen peroxide-inducible proteins in Salmonella typhimurium overlap with heat shock and other stress proteins. Proc Natl Acad Sci USA 83, 8059-8063.

Navarro, R. E. \& Aguirre, J. (1998). Posttranscriptional control mediates cell type-specific localization of catalase A during Aspergillus nidulans development. J Bacteriol 180, 5733-5738.

Navarro, R. E., Stringer, M. A., Hansberg, W., Timberlake, W. E. \& Aguirre, J. (1996). catA, a new Aspergillus nidulans gene encoding a developmentally regulated catalase. Curr Genet 29, 352-359.

Piper, P. (1997). The yeast heat shock response. In Yeast Stress Responses, pp. 75-99. Edited by S. Hohmann \& W. H. Mager. Berlin \& Heidelberg: Springer.

Sambrook, J., Fritsch, E. F. \& Maniatis, T. (1989). Molecular Cloning: a Laboratory Manual, 2nd edn. Cold Spring Harbor, NY : Cold Spring Harbor Laboratory.

Santoro, N. \& Thiele, D. J. (1997). Oxidative stress responses in the yeast. In Yeast Stress Responses, pp. 171-211. Edited by S. Hohmann \& W. H. Mager. Berlin \& Heidelberg: Springer.

Scandalios, J. G. (1990). Response of plant antioxidant defense genes to environmental stress. Adv Genet 28, 1-41.

Sweeley, C. C., Bentley, R., Makita, M. \& Wells, W. W. (1963). Gas-liquid chromatography of trimethylsilyl derivatives of sugars and related substances. J Am Chem Soc 85, 2497-2507.

Tauber, A. I. \& Babior, B. M. (1977). Evidence for hydroxyl radical production by human neutrophils. J Clin Invest 60, 374-379.

Thevelein, J. M. (1996). Regulation of trehalose metabolism and its relevance to cell growth and function. In The Mycota III, Biochemistry and Molecular Biology, pp. 395-420. Edited by R. Brambl \& G. A. Marzluf. Berlin \& Heidelberg: Springer.

Wieser, R., Adam, G., Wagner, A., Schuller, C., Marchler, G., Ruis, H., Krawiec, Z. \& Bilinski, T. (1991). Heat shock factor-independent heat control of transcription of the CTT1 gene encoding the cytosolic catalase $\mathrm{T}$ of Saccharomyces cerevisiae. J Biol Chem 266, 12406-12411.

Received 23 February 1999; revised 15 June 1999; accepted 8 July 1999. 